\title{
NEET BY CHOICE? INVESTIGATING THE LINKS BETWEEN MOTHERHOOD AND NEET STATUS
}

\author{
Sean Molloy, Deborah Potter
}

The Ministry for Women

\begin{abstract}
:
This paper investigates the propensity of young mothers aged 15 to 24 to be not in employment, education and training. Not all young mothers are out of labour force and many are involved in education. Additionally, those that are NEET may not be by choice. We identify areas for further investigation and policy response.
\end{abstract}

The views, opinions and conclusions expressed in this report are intended to inform and stimulate wider debate. They do not represent government policy.

\section{Introduction}

It is tempting for policy-makers to subtract young mothers aged 15 to 24 from the NEET group, assuming young mothers have intentionally disengaged with employment, education and training due to their involvement in a caregiving role. This paper tests this assumption and identifies that not all NEET young mothers are out of the labour force by choice.

We find that nearly half of young mothers aged 15-24 are in education and/or employment, and therefore not classified as NEET. Unemployment rates for single mothers aged 15-25 are higher than for single females, partnered females without children and partnered mothers. This indicates that single mothers are experiencing greater difficulty securing work than other women in their age group.

NEET is a commonly-used labour market term which describes those aged between 15-24 years who are not in employment, education or training. NEET rates are of interest to policy-makers looking to improve educational and labour market outcomes. They are used as a rough gauge of successful transition between the secondary education system and further training or employment. Statistics New Zealand (2011) notes that the development of the NEET indicator in the New Zealand context was intended to help monitor and inform "young people's disadvantages, disengagement, and underutilisation in the labour market", in light of intensified interest in the outcomes of young people in the labour market following the Global Financial Crisis (GFC).

Young people are more likely to be negatively affected by economic crises, and this has been the case in New Zealand. The OECD (2013) noted that New Zealand's increase in youth unemployment and NEET rates post-GFC were among the largest in the OECD. Unemployment rates for 15 to 19 year-olds climbed to over 20 percent from March 2010 with an unemployment rate of just over 23 percent for both sexes in March 2014. Like young people, Māori and Pacific women also fared badly in the GFC with unemployment rates roughly three times higher than European women and consistently higher than Pacific and Mãori men. 
Table 1: NEET Rates Youth Labour Force (March 2014)

\begin{tabular}{|c|c|c|c|}
\hline & $\begin{array}{c}\text { Aged 15-19 } \\
\text { years }\end{array}$ & $\begin{array}{c}\text { Aged 20-24 } \\
\text { years }\end{array}$ & $\begin{array}{c}\text { Total aged 15-24 } \\
\text { years }\end{array}$ \\
\hline Male & 7.7 & 10.2 & 9 \\
\hline Female & 8.8 & 19.7 & 14.5 \\
\hline $\begin{array}{c}\text { Total Both } \\
\text { Sexes }\end{array}$ & 8.2 & 14.8 & 11.7 \\
\hline
\end{tabular}

Female NEET rates are consistently higher than male NEET rates, particularly in the 20-24 year age group (as seen in Table 1 above). The difference is commonly understood to be driven by females parenting or undertaking wider 'caring responsibilities'. NEET rates for females and males are roughly the same once mothers and caregivers are subtracted.

Figure 1: NEET Rates 15- 24 years by Ethnicity and Sex (March 2014)

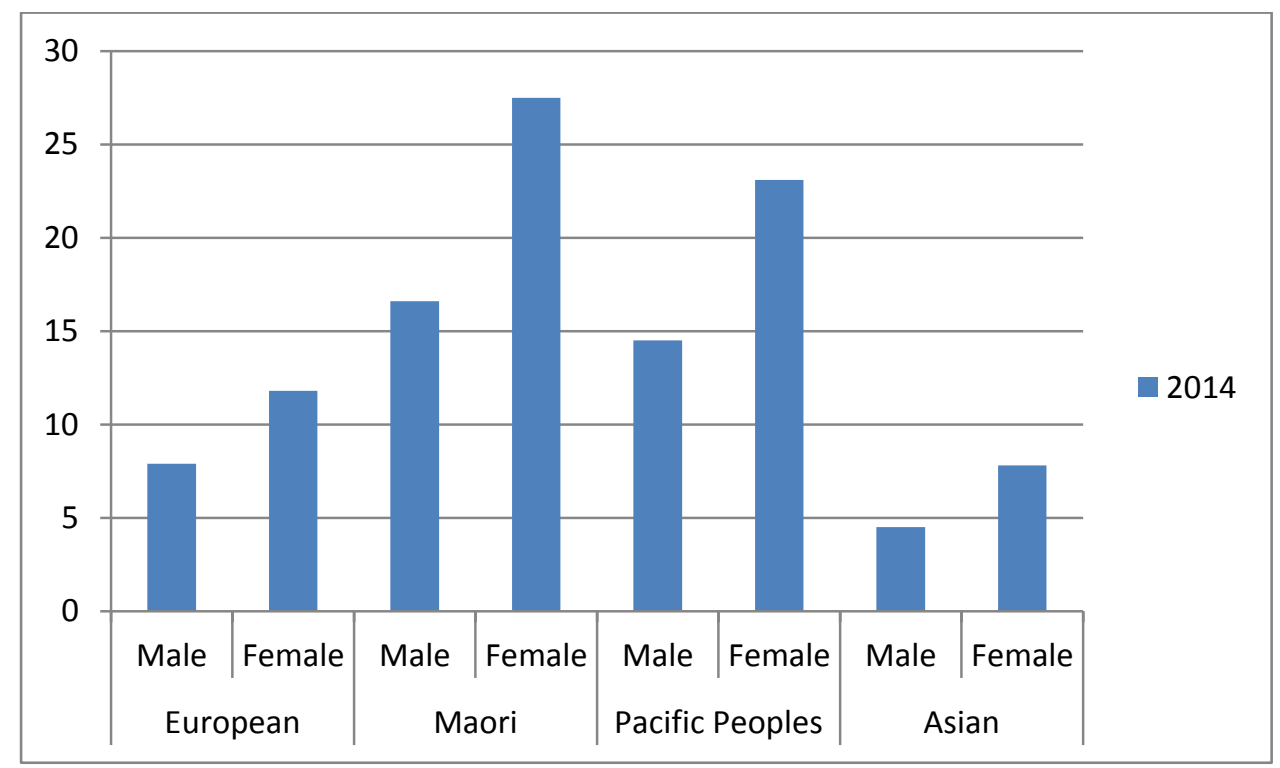

NEET rates vary between ethnic groups as seen in Figure 1. More than a quarter of young Māori women and just under a quarter of young Pacific women were NEET in March 2014.

The majority of births to mothers under twenty years are to older teens aged 17 -19 years. Māori women are more likely to be teenaged mothers than other ethnic groups. In 2006, 9.3 percent of Māori teenage women were mothers, compared to 5.4 percent of Pacific teenage women, and 3.2 percent and 1 percent of European and Asian teenaged women (Families Commission, 2011).

It is important to bear in mind that Māori and Pacific women will be highly represented in the NEET group and that policy responses discussed in the final section need to be culturally aligned to be effective. It is also worth noting that negative views on 'teenage pregnancy' by wider society are influenced by culture, and that Māori whanau may not necessarily view teenage pregnancy as problematic (Families Commission 2011). Young Māori parents can themselves see parenthood as a positive opportunity to reconnect with their whanau, improve their own self-esteem, and to gain a sense of direction and purpose. Miller (2012) notes that 
research is challenging a causal association between teenage parenthood and poor outcomes, and those differences in outcomes arise from socio-economic factors.

With these socio-cultural themes in mind, the next section uses the New Zealand Household Labour Force Survey data to explore the propensity of young mothers aged 15 to 24 to be NEET, or willingly not in the labour force.

\section{Data description}

Our analysis used March quarter data from the Household Labour Force Survey from 2005 2014. We investigated employment and education participation for young women aged $15-24$ by parenting status. We compared NEET rates for young women who were caregiving compared to those who were not parents. We also looked at the impact of relationship status.

\section{Findings}

Just under half of young mothers were undertaking education and/or paid working March 2014 . NEET rates are much higher for young mothers than those who are not caregiving.

Figure 2: NEET Rates for Females by age and parenting status (March 2014)

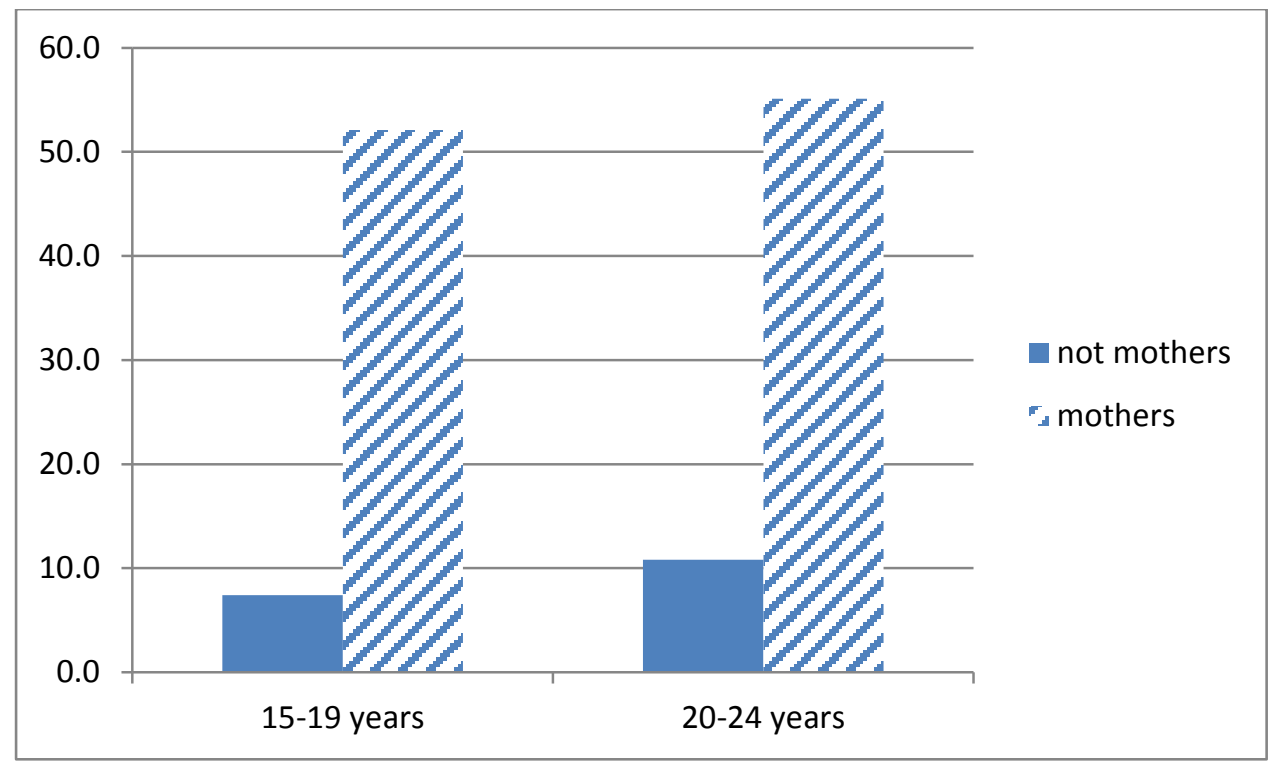

Figure 3 indicates that from 2005 NEET rates for both age groups have shown a small decline, with the rate for 15-19 year olds showing the most decrease. The decline may be associated with an increase in teen parenting units although a 2011 ERO report estimated that in 2009 only approximately 5 percent of teen parents enrol in these facilities (Education Review Office 2011). 
Figure 3: NEET Rates for Young Mothers (Mar 2005 -14)

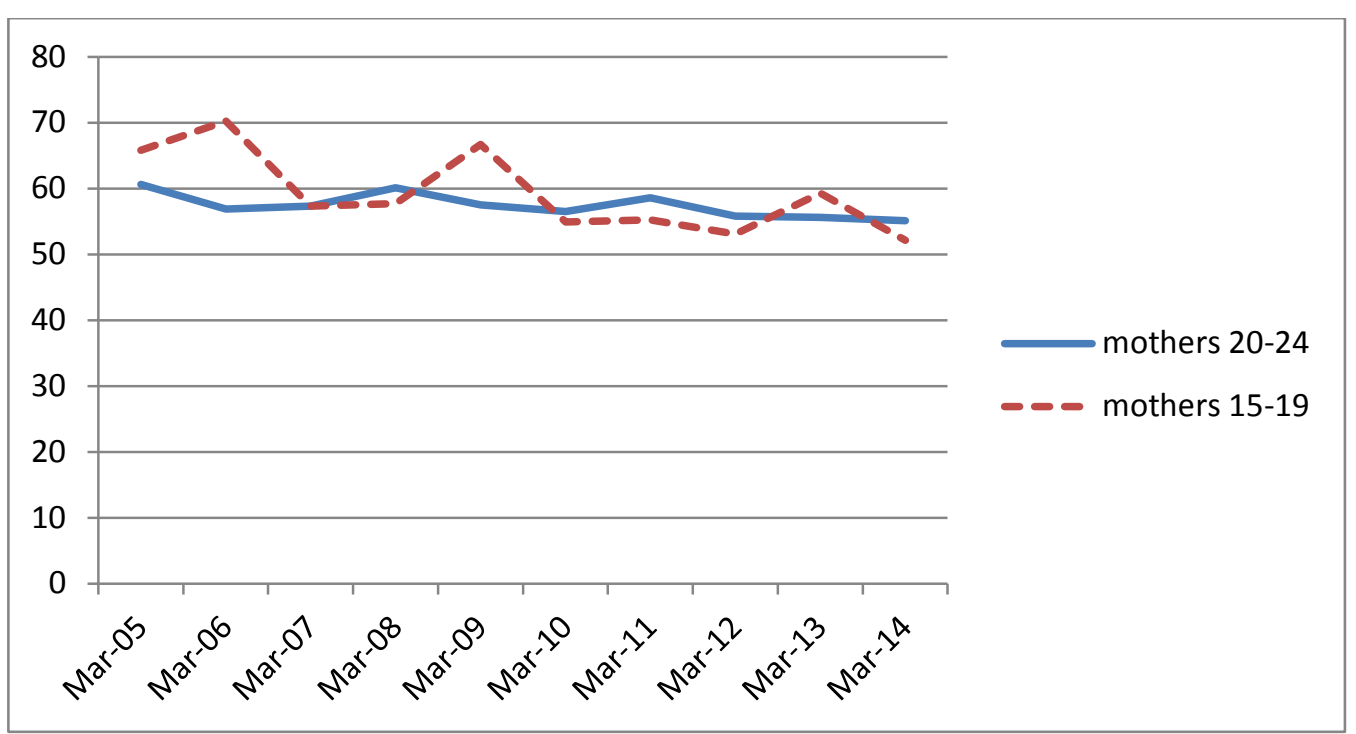

In March 2014 one in five women aged 20-24 were parents $(n=32,300)$ while only 3 percent of women aged 15- 19 years were parents $(n=4700)$. The proportion of women who were mothers in the older age group has shown a slight decline since 2005, in line with an increasing average age of first child for New Zealand women. The small proportion of mothers under twenty has remained stable.

The estimated number of 15 - 19 year old NEET mothers in March 2014 was 2500. The number of NEET 20-24 year olds is much larger at 17,000.

For the remainder of this paper we collapse the NEET-aged female population into one group of 15-24 years. In this way we can more reliably consider partnership status in relationship to labour force participation and education.

Figure 4: Unemployment rates for females aged 15-24 by relationship and parent status

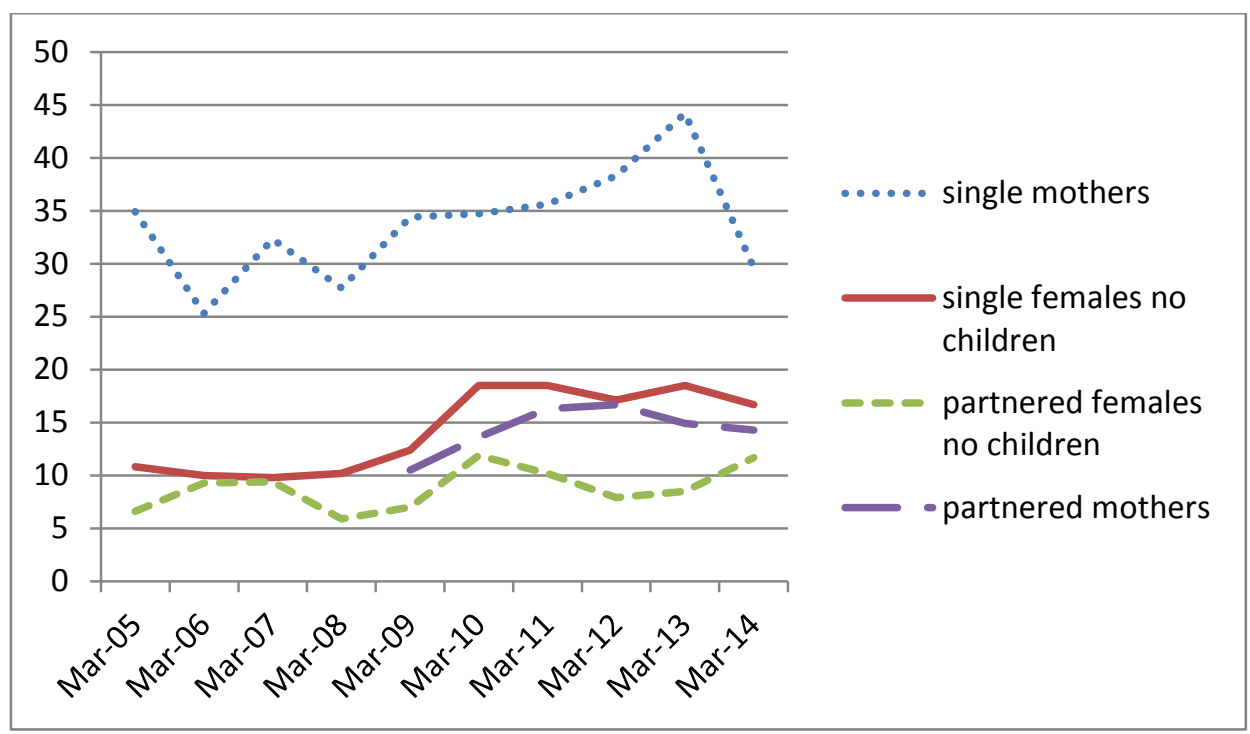


Unemployment rates for single mothers were higher than for single females, partnered females without children and partnered mothers. This indicates that single mothers are experiencing greater difficulty securing work than other women in their age group. (Partnered mothers with children are a small group for which estimates can only be provided from 2009.)

Single mothers are engaging with education (Fig 5 below), but at lower levels than women their age without children. Partnered females are likely to be older on average. Their lower engagement with education can be explained by a higher employment rate (see figure 6 below) and a larger proportion having completed their education.

Figure 5: Educational participation females 15-24 by partnership and parent status

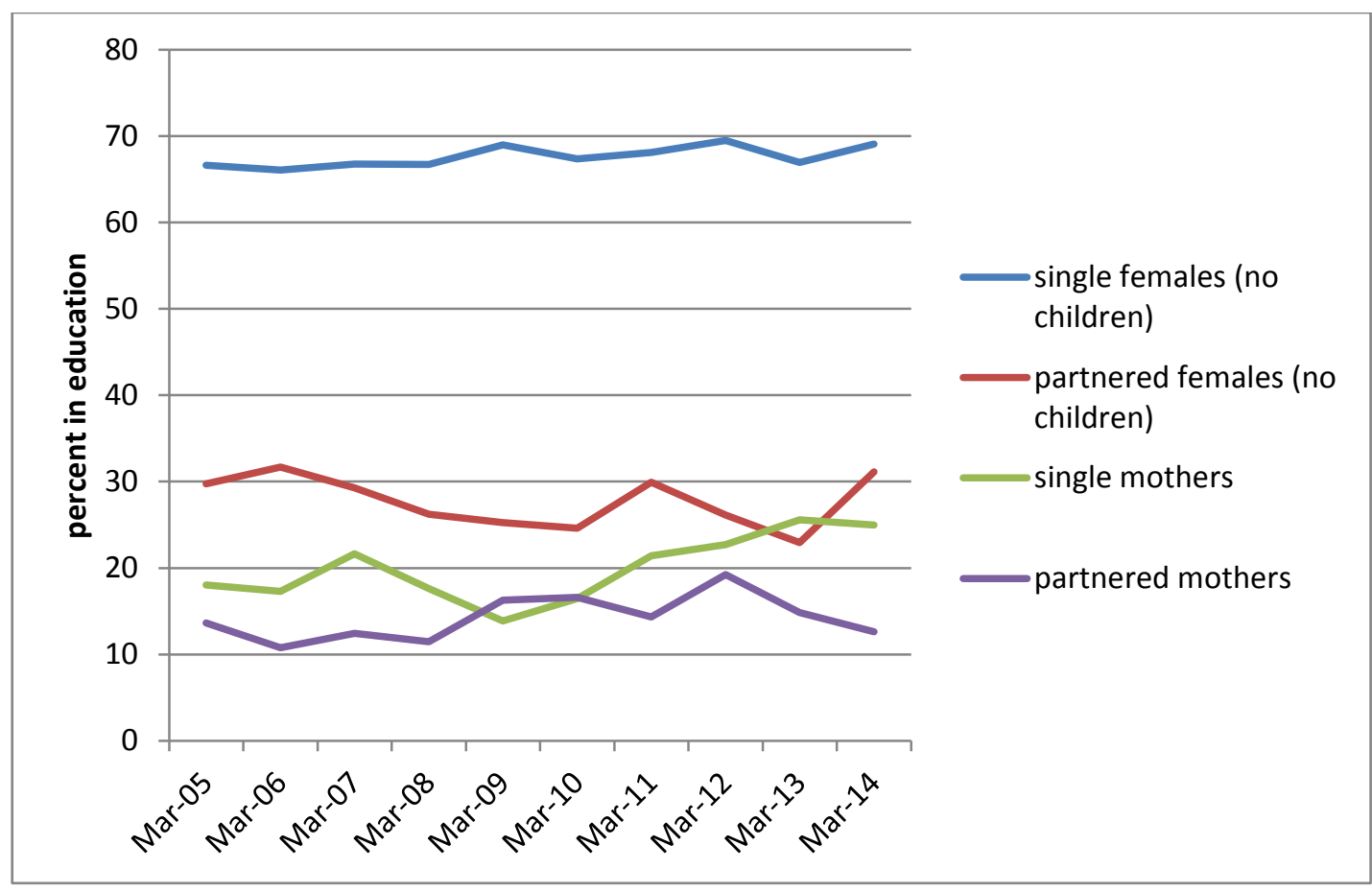

Figure 6 combines the mutually exclusive categories of labour force status with NEET rates to infer each group's interaction with education and its relationship to 'not in the labour force' status. Education can be synonymous with all three labour force categories.

The chart indicates that almost all single females without children who are not in the labour force can be understood as intentionally engaged in education. The diamond appearing slightly below the proportion who are unemployed is explained by those who are staying in education while actively job seeking.

The NEET indicator for both partnered and non-partnered mothers indicates that a large part of those not in the labour force could be explained by parenting. However neither group's NEET indicator sits level with employment and both groups contain a proportion of unemployed women. Unemployment is a strong indicator of wanting to engage with the paid labour force. 
Figure 6: Employment status and NEET rate females 15-24 years (March 2014)

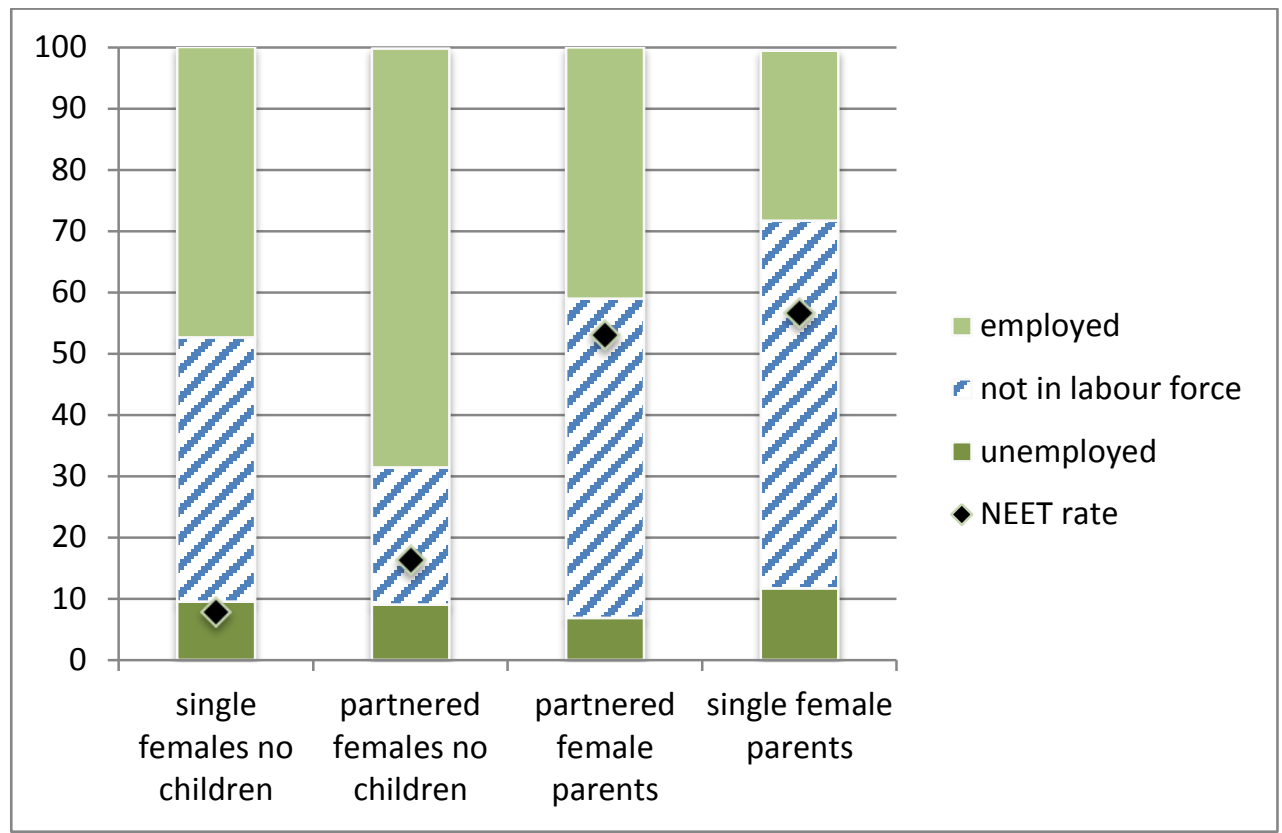

It can be argued that mothers face a higher bar to achieve 'unemployed' status as they must have childcare organised in order to be 'ready to start work' (as well as 'actively seeking work'). In addition not all work is suitable for parents if hours are uncertain or cannot be reconciled against childcare availability. For this reason the unemployment measure can undercount women's attempting to obtain paid work, particularly single mothers.

The Household Labour Force Survey does not contain an indicator of unsuccessful engagement with education; however the New Zealand Childcare Survey 2009 provides some context. The survey reported that:

- Ten percent of studying mothers had problems with childcare

- A quarter of single parents studying had had childcare problems in the last 12 months

- A third of those mothers who had problems had quit studying and

- Cost and the time available were the most common reasons given.

From this we can infer that educational participation by young mothers may not be low by choice.

\section{Further research:}

This research can be viewed as preliminary. There is a need to further investigate barriers for young mothers to undertaking education, particularly tertiary level education and training. Trends and outcomes in later educational take up for women who become mothers aged 15 24, potentially utilising emerging administrative data sources.

More understanding of cultural differences between young mothers will enhance policy responses. Evaluation of cross agency responses could improve outcomes for young mothers in a policy environment where early childhood, secondary and tertiary education, and social services intersect. 


\section{Discussion:}

Policy-makers may fail to address the needs of mothers seeking education or work (but who are facing issues accessing those) if they dismiss the higher NEET rates for women because of caregiving roles.

Figure 7: Unemployment Rates by Sex and Age (March 2014)

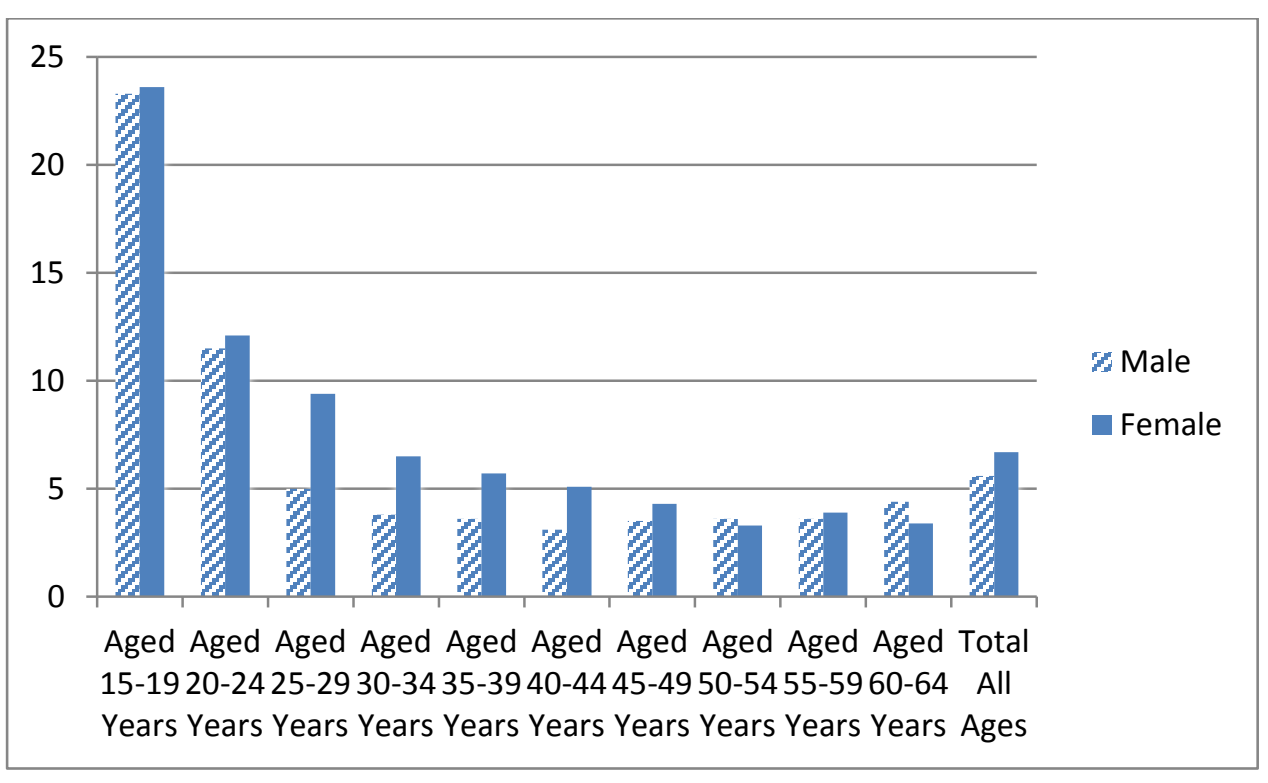

Figure 7 shows that women experience higher rates of unemployment than men through much of adulthood. Assuming that higher NEET rates are acceptable for young mothers may contribute to a policy environment that does not pay sufficient regard to the difficulties of labour market engagement for working mothers in general.

Our investigation has identified that not all young mothers are out of labour force (or education) by choice. In particular:

- Just under half of young mothers aged 15-24 are in education or paid employment, and therefore not classified as NEET

- unemployment rates for single mothers aged 15-25 are higher than single females, partnered females without children and partnered mothers.

We believe this indicates that single mothers are experiencing greater difficulty securing work than other women in their age group.

We infer that educational participation by young mothers may not be low by choice based on data from New Zealand Childcare Survey 2009.

If a significant number of young mothers aged 15-24 are wishing to engage in education or the labour market, what can be done about this?

Ideally, young mothers should be supported into study or work-based learning in order to lift their level of skills for the labour market. The OECD (2013) noted that rapid and profound 
structural changes have given rise to strong skill biases in OECD labour demand, which put young people at a disadvantage while requiring longer studies.

Statistics New Zealand (2014) examined mothers aged 25 to 45 years, and found that tertiaryqualified single mothers have similar employment rates as all tertiary-qualified women, but that tertiary-qualified single mothers were a relatively small group of the total group of single mothers.

The Ministry of Women's Affairs E Tū Ake! Stand Tall and Proud (2014) report outlines interventions to support low income women, including young mothers and young single mothers. The report notes the importance of providing pastoral care/support for young mothers that is responsive to their particular circumstances. Research indicates that the most effective programmes in this area offer multiple forms of support and combine the contributions of multiple stakeholders. The Ministry is interested in assisting young mothers/NEET women to transition into sustainable well-paid employment. One way the Ministry is doing this is by working with providers to consider how to attract young Maori and Pacific mothers into trades training.

An important existing policy intervention in this space is the Youth Services programme, in which community-based providers work with young people to support them into education, training or work-based learning. Young people can be referred or identified by providers. This programme is now being expanded to include 18 and 19 year-olds.

Another existing policy intervention are Teen Parent Units (TPUs) which support pregnant young women and mothers to continue studying.. These units are administratively attached to a host state school. TPUs have the benefit of combining education and childcare, and some positive stories are emerging from the limited evaluation literature. There may be scope to expand the overall number or size of TPUs. TPUs are limited to supporting secondary schoollevel learning. It would be interesting to explore how a TPU-style model might be used to bridge the gap between secondary and tertiary level education.

This research has found that not all NEET-aged mothers are NEET and challenges assumptions that those that are NEET are comfortably so. This has implications for how we view gender differences in NEET rates. We do not advocate a one-size-fits-all model to respond to educational and labour market engagement for young mothers and note some encouraging responses underway across government .

\section{References}

Education Review Office (2011). Evaluation of Teen Parent Units. Wellington: Education Review Office.

Education Review Office (2014). Evaluation of Teen Parent Units. Wellington: Education Review Office.

Families Commission (2011). Teenage pregnancy and parenting: an overview, Wellington, Families Commission 
Miller, J. (2012). Re-storying identities: Young women's narratives of teenage parenthood and educational support, Thesis submitted in partial fulfilment of the requirements for Doctor of Philosophy in Education, University of Canterbury

OECD (2013). Economic Surveys New Zealand June 2013, OECD

Statistics New Zealand (2010). New Zealand Childcare Survey 2009 (revised December 2011) Wellington: Statistics New Zealand http://www.stats.govt.nz/ /media/Statistics/Browse\%20for\%20stats/ChildcareSurve y/HOTP2009revised/ChildcareSurvey2009revisedHOTP.pdf

Statistics New Zealand (2011). Introducing the youth not in employment, education, or training indicator. Wellington: Statistics New Zealand http://www.stats.govt.nz/ /media/Statistics/browse-categories/incomework/employment-unemployment/young-people-employment-educationtraining/young-people-employment-education-training.pdf

Statistics New Zealand (2014). Mothers in the New Zealand Workforce, Labour Employment and Work Conference 16 (forthcoming) 